\title{
Calculation of Enclosure Index for Assessing Urban Landscapes Using Digital Surface Models
}

$\operatorname{AUTHOR}(\mathrm{S})$ :

Susaki, Junichi; Komiya, Yuto; Takahashi, Kenryo

\section{CITATION:}

Susaki, Junichi ... [et al]. Calculation of Enclosure Index for Assessing Urban Landscapes Using Digital Surface Models. IEEE Journal of Selected Topics in Applied Earth

Observations and Remote Sensing 2014, 7(10): 4038-4045

ISSUE DATE:

2014-10

URL:

http://hdl.handle.net/2433/193285

\section{RIGHT:}

(C) 2014 IEEE. Personal use of this material is permitted. Permission from IEEE must be obtained for all other uses, in any current or future media, including reprinting/republishing this material for advertising or promotional purposes,

creating new collective works, for resale or redistribution to servers or lists, or reuse of any copyrighted component of this work in other works.; This is not the published version. Please cite only the published version.; この論文は出版社版

でありません。引用の際には出版社版をご確認ご利用ください。 


\title{
Calculation of Enclosure Index for Assessing Urban Landscapes Using Digital Surface Models
}

\author{
Junichi Susaki, Yuto Komiya, Kenryo Takahashi \\ Graduate School of Engineering, Kyoto University Nishikyo-ku, Kyoto 615-8540, Japan \\ E-mail: susaki.junichi.3r@kyoto-u.ac.jp
}

\begin{abstract}
Local governments in Japan need to assess landscape quality from the perspective of aesthetics before approving new construction. However, ground surveys are time-consuming and expensive to perform over wide areas. This paper proposes a methodology using a digital surface model (DSM) to estimate a local landscape index, referred to as the "enclosure index", in urban areas. The index is defined as the ratio of occluded area to the entire field of view. The index can be applied to local landscape assessment from the viewpoint of a human, and it is expected to allow for estimating the landscape quality over a wide area at low cost. The index is defined in two different projections, and two types of DSMs for calculating the index were investigated: DSM from airborne LiDAR (LiDAR-DSM) and DSM generated from stereoscopic aerial images (Image-DSM). Enclosure index (occlusion) maps were generated, and the indices were calculated in the study area of Higashiyama, Kyoto, Japan. As a result of validation based on ground truth data, it was found that the index from LiDAR-DSM was more accurate than that from Image-DSM because the height accuracy of LiDAR-DSM was higher than that of Image-DSM, especially for narrow streets, where three-dimensional coordinates are difficult to restore by using aerial images. Even though last-pulse mode LiDAR data may yield underestimated DSM, it was found that the proposed methodology is effective for estimating the index over a wide area at low cost.
\end{abstract}

Index Terms --- Urban areas, Geospatial analysis

\section{Introduction}

Regulation of new building construction in urban areas is necessary for preserving or improving local landscape quality. In Japan, the Landscape Act was passed in 2004 in order to build and preserve beautiful landscapes as well as to create attractive and comfortable living environments. The national government, local governments, businesses and local residents are encouraged to share the 
responsibility to promote the development of aesthetically pleasing landscapes [1]. For example, Nishinomiya City in Hyogo Prefecture, Japan, enacted a regulation for a specific residential area to the effect that newly constructed houses should have a green space ratio of at least 15\% (proportion of the vegetation area to the whole visible area). The regulation specifies a simple formula for calculating the green space ratio [2]. Local governments need to assess landscape quality from the perspective of aesthetics before approving new construction. The landscape index is calculated through ground surveys by local government officials. However, such surveys are time-consuming and expensive to extend over a wide area. Accordingly, it is difficult to apply the regulation to the entire city. Therefore, a simple and effective approach to assess local landscape is required.

Remote sensing may be capable of measuring local landscape indices over a large area at low cost. Height data are necessary to assess local landscape from the viewpoint of a human. Airborne light detection and ranging (LiDAR) is useful for generating digital surface models (DSMs) over wide areas. On the other hand, stereoscopic aerial images can generate DSMs through photogrammetric processing. Because an archive of aerial images is much more than that of LiDAR data in Japan, DSMs generated from aerial images may be used for local landscape assessment in terms of data availability. Hereafter, DSMs generated using LiDAR and aerial images are called LiDAR-DSM and Image-DSM, respectively. In general, the height accuracy of Image-DSM is lower than that of LiDAR-DSM.

The use of LiDAR-DSM in local landscape assessment has been reported, but many of the previous studies have focused on vegetation and forest canopy structure [3-5]. Application to urban landscape assessment entails classifying point clouds into different objects and evaluating the object arrangement and percentage as seen from overhead [6-10]. For example, Yu et al. [11] estimated urban density such as building coverage ratio and floor area ratio, and Alexander et al. [12] visualized roofs of buildings from LiDAR-DSM. However, urban landscape assessment taking into account the human sense of aesthetics should be conducted from the perspective on the ground, and accomplishing this is the aim of this study. To the authors' knowledge, no such method has been reported. In addition, LiDAR-DSM and Image-DSM have yet to be compared in terms of landscape index accuracy.

In this paper, we focus on an important landscape index known as "enclosure index" and propose a methodology for estimating this index using DSMs. The enclosure index is defined as the ratio of the area occluded by objects to the entire visible area. This paper reports on methodology for 
estimating the enclosure index from the viewpoint of human aesthetics by using DSM obtained from remote sensing.

An overview of the newly proposed method is given in Section 2. The locations used in the study and the data collected from these sites are presented in Section 3. The experimental results are reported in Section 4. The results, the validity of the algorithm and a comparison between LiDAR-DSM and Image-DSM in terms of estimation accuracy are discussed in Section 5. Section 6 concludes the paper.

\section{Methodology}

\subsection{Overview of Enclosure Index}

As mentioned in Section 1, the enclosure index is defined as the ratio of the area occluded by objects to the entire visible area. The basic idea behind identifying the occluded area is varying the azimuth from $0^{\circ}$ to $360^{\circ}$ and determining the maximum elevation angle at which the view is occluded by objects. First, we present two definitions of the enclosure index expressed in different projections. Next, we briefly introduce a method for interpolating the height of invalid cells for LiDAR-DSM. LiDAR-DSM data are originally point data, which are subsequently converted into grid data for simple coding. An interpolation technique is necessary because some cells have no valid height. Finally, we describe the calculation of the enclosure index from DSM data.

\subsection{Enclosure Index 1}

Figure 1 shows the viewable area from the viewpoint of a person of height $h$ in the direction of the azimuth $\phi$. We assume that $\phi$ and the elevation angle $\theta$ are divided into intervals $\Delta \phi$ and $\Delta \theta$, respectively. We vary the value of $\phi$ in steps of $\Delta \phi$ from $0^{\circ}$ to $360^{\circ}-\Delta \phi$ and determine the maximum elevation angle $\theta_{\max }$ at which occlusion occurs due to objects within the maximum range $D_{\max }$ at each $\phi$. Then, a function of occlusion, given by Eq. (1), is generated.

$$
f(\phi, \theta)=\left\{\begin{array}{lc}
1: & \text { occluded } \\
0: & \text { not occluded }
\end{array}\right.
$$

As a result, we can generate a map similar to that shown in Figure 2(a) (referred to as occlusion map below). Enclosure index $E I_{1}$ in azimuth-elevation angle space is given by 


$$
E I_{1}=A_{2} /\left(A_{1}+A_{2}\right) \times 100=\sum_{\phi=0}^{360-\Delta \phi} \sum_{\theta=-90}^{90} d s_{1}(\phi, \theta) f(\phi, \theta) / \sum_{\phi=0}^{360-\Delta \phi} \sum_{\theta=-90}^{90} d s_{1}(\phi, \theta) \times 100
$$

where $A_{1}$ and $A_{2}$ denote the sky area and the occluded area in azimuth-elevation angle space, respectively, and $d s_{1}(\phi, \theta)$ denotes an area of a cell in Figure 2(a). $d s_{1}(\phi, \theta)$ is given by

$$
d s_{1}(\phi, \theta)=\Delta \phi \Delta \theta
$$

According to Eq. (2), $E I_{1}$ can be from 0 to $100 \%$.

\subsection{Enclosure Index 2 (equisolid angle projection)}

Although it has the advantage of simple calculation, $E I_{1}$ also has the disadvantage that it exaggerates areas at large values of $\theta$. For example, a point at an elevation angle of $90^{\circ}$ is projected onto an area defined by the intervals $\left[90^{\circ}-\Delta \theta / 2,90^{\circ}+\Delta \theta / 2\right]$ and $\left[0^{\circ}-\Delta \phi / 2,360^{\circ}-\Delta \phi / 2\right]$ in Figure 2(a). Instead, an equisolid angle projection (Figure 2(b)) may be more useful for evaluating the degree of enclosure because all unit areas in the space are equal. In this research, an enclosure index evaluated in equisolid angle projected space is defined as enclosure index $2\left(E I_{2}\right)$.

Let us calculate the area $d s_{2}(\phi, \theta)$ of a finite element in equisolid angle projection where the azimuth range is [ $\phi-\Delta \phi / 2, \phi+\Delta \phi / 2]$ and the elevation angle range is [ $\theta-\Delta \theta / 2, \theta+\Delta \theta / 2] . \Delta \phi$ and $\Delta \theta$ denote intervals of $\phi$ and $\theta$, respectively. Assume that this finite element is located on the surface of a sphere of radius $R$. In this case, $d s_{2}(\phi, \theta)$ (which is independent of $\phi$ and dependent on $\theta$ ) is expressed as

$$
d s_{2}(\phi, \theta)=(R \cos \theta \Delta \phi)(R \Delta \theta)=R^{2} \cos \theta \Delta \phi \Delta \theta
$$

Therefore, $E I_{2}$ can be calculated from the following:

$$
E I_{2}=B_{2} /\left(B_{1}+B_{2}\right) \times 100=\sum_{\phi=0}^{360-\Delta \phi} \sum_{\theta=-90}^{90} d s_{2}(\phi, \theta) f(\phi, \theta) / \sum_{\phi=0}^{360-\Delta \phi} \sum_{\theta=-90}^{90} d s_{2}(\phi, \theta) \times 100
$$

where $B_{1}$ and $B_{2}$ denote the area corresponding to the sky and the occluded area in equisolid angle projected space, respectively. An occlusion function, $f(\phi, \theta)$ is same as that given by Eq. 1 used to calculate $E I_{1}$. Actual calculation using Eq. 5 is rather time-consuming because $d s_{2}(\phi, \theta)$ is dependent on $\theta$ while $d s_{1}(\phi, \theta)$ is constant. 


\subsection{Interpolation of LiDAR-DSM data points}

In the case of searching for $\theta_{\max }$ (Fig. 1), grid-based DSM data are more suitable than point cloud data because processing using grid-based DSM data is simpler and more efficient. Original point cloud data can be converted into grid data by assigning points to the nearest respective cells. However, there are many invalid cells without height data $z$ in the case of LiDAR-DSM. Therefore, interpolation of DSM data is indispensable before calculating the enclosure index.

Inverse distance weighted interpolation is employed because of its simple implementation. The weights of the data available for the interpolation are assigned such that they are inversely proportional to the distances from the target point. Assume that a cell has coordinates $\left(x_{p}, y_{p}, z_{p}\right)$, and $z_{p}$ is unknown. Cells with valid heights whose coordinates are $\left(x_{i}, y_{i}, z_{i}\right)$ are searched within a window of a certain area. $z_{p}$ is interpolated when a sufficient number of valid cells are available within the window:

$$
z_{p}=\frac{\sum_{i=1}^{n} \omega_{i} z_{i}}{\sum_{i=1}^{n} \omega_{i}}
$$

where

$$
\omega_{i}=\frac{1}{\sqrt{\left(x_{i}-x_{p}\right)^{2}+\left(y_{i}-y_{p}\right)^{2}}}
$$

Iterative interpolation is implemented until no invalid cells remain.

\subsection{Calculation of Enclosure Index}

We can calculate the enclosure index of a specific cell as follows. Assume that $\phi$ is fixed. Figure 3 illustrates a search when $|d x| \leq|d y|$, i.e., $45^{\circ} \leq \phi \leq 135^{\circ}$ and $225^{\circ} \leq \phi \leq 315^{\circ}$. Cells at a certain position along the $y$ axis that share the same direction are used to interpolate the height $z$ along the $y$ axis. The interpolation weights are assigned such that they are inversely proportional to the distance from the point to the cell center. When $|d x|>|d y|$, cells at a certain position along the $x$ axis that share the direction arrow are used to interpolate height along the $x$ axis. Eventually, the elevation angle $\theta$ is calculated with respect to the interpolated height. $\theta_{\max }$ is selected among a set of $\theta$ values within the maximum range $D_{\max }$. In an occlusion map in the azimuth-elevation angle space (Figure 2(a)), the range $\left[-90^{\circ}, \theta_{\max }\right]$ at $\phi$ is regarded as occluded. The occlusion map is completed by changing the value 
of $\phi$ from $0^{\circ}$ to $360^{\circ}-\Delta \phi$, and $E I_{1}$ is calculated by using Eq. (2). $E I_{2}$ can be calculated by using the occlusion map of $E I_{1}$ and Eq. (5).

\section{Study Area and Data Used}

Higashiyama Ward in Kyoto, Japan, was selected as the study area (Figure 4). Higashiyama is hilly and contains traditional temples and shrines. This area is expected to allow for convenient assessment of landscape including not only gardens inside temples and shrines, but also streets and roads. In particular, viewpoints from many narrow streets, approximately $5 \mathrm{~m}$ in width, are indispensable for assessing the landscape in this area.

Airborne LiDAR data were acquired in June 2002, and the data density was approximately 1.0 points $/ \mathrm{m}^{2}$. The horizontal and vertical accuracies were $\pm 50 \mathrm{~cm}$ and $\pm 15 \mathrm{~cm}$, respectively. Last-pulse mode data were available, and aerial stereo images of the study area acquired using a UCX camera on November 17, 2007, were also available. Tie points present in more than one image were automatically obtained, and DSM was generated with the software packages Match-AT version 5.4 [13] and Match-T version 5.4 [14], respectively. Tie points were used to determine the relative positions and orientations of cameras. Orthogonal projection images were generated by using a 50-m mesh digital elevation model (DEM) published by the Geospatial Information Authority of Japan [15]. DEM was generated from topographic maps at a scale of 1:25,000. As a result, grid-based DSMs with a spatial resolution of $1 \mathrm{~m}$ were prepared.

\section{Results}

\subsection{Estimated Enclosure Index}

In the experiment, $D_{\max }$ was set to $100 \mathrm{~m}$ through empirical examination. $h$ was set to $1.5 \mathrm{~m}$ in consideration of the viewpoint of a human. $\Delta \phi$ and $\Delta \theta$ were set to $1.0^{\circ}$. The enclosure index was calculated by applying the methodology described in Section 2 .

For estimation using LiDAR data, original airborne LiDAR data were first converted into grid data and subsequently into DSM images. The grid size was set to $1.0 \mathrm{~m}$. The airborne LiDAR data were filtered following [16], and digital terrain model (DTM) images without any invalid cells were generated. DSM images were interpolated when more than 4 valid cells were available within a $5 \times 5$ window. The index was calculated at ground points where the DSM value was equal to the DTM value. The $E I_{1}$ distribution of the study area is shown in Figure 5. 
For estimation using Image-DSM, the index was calculated at the cells where it was calculated using LiDAR-DSM. Because it was difficult to filter ground data from Image-DSM data, the ground data obtained by filtering using LiDAR-DSM were used. The reason for this difficulty was that the boundaries between roads and buildings in DSM were not as clear as those of LiDAR-DSM. The $E I_{1}$ distribution in the study area is shown in Figure 6.

\subsection{Validation}

On-site measurement of the enclosure index was conducted using a digital camera (Canon EOS Kiss X5) with a fisheye lens (Sigma 4.5 mm F2.8 EX DC). The assessment was conducted using 30 data points shown in Figure 4. Figure 7 shows sample images. Two images were taken forward and backward along the horizontal optical axis at $1.5 \mathrm{~m}$ height. Areas corresponding to the sky were extracted semi-automatically and corrected manually. The lens used was designed to produce equisolid angle projection, and thus the areas corresponding to the sky and the enclosure index were easily calculated. The sum of the sky areas in the forward and backward images are equivalent to $B_{1}$ of Figure 2. With these sky areas, $f(\phi, \theta)$ is generated and then $E I_{2}$ was calculated. $E I_{1}$ was calculated by using $f(\phi, \theta)$ and the factor $\cos \theta$ given by Eq. 4. The results for $E I_{1}$ and $E I_{2}$ calculated from LiDAR-DSM and Image-DSM are shown in Figures 8(a) and 8(b), respectively. The root mean square errors (RMSEs) for the four cases were $2.85 \%$ and $2.72 \%$ for $E I_{1}$ and $E I_{2}$ from LiDAR-DSM, respectively, and $6.63 \%$ and $5.40 \%$ for $E I_{1}$ and $E I_{2}$ from Image -DSM, respectively.

\section{Discussion}

\subsection{Comparison of results obtained from LiDAR-DSM and Image-DSM}

In order to compare the two DSMs, their horizontal and vertical accuracies should be examined. However, the horizontal and vertical accuracies of Image-DSM were not clear in this study. Therefore, it was compared with LiDAR-DSM, whereby the differences in height at 30 points located on roads were calculated for Image-DSM and LiDAR-DSM (Figure 9). While LiDAR-DSM is not guaranteed to be highly accurate ( $\pm 50 \mathrm{~cm}$ for horizontal and $\pm 15 \mathrm{~cm}$ for vertical accuracies), heights at points on major roads can be used for such comparison. It was shown that the heights of points at narrow streets for Image-DSM were not reliable. Figure 10 shows the relation between $\mathrm{road} / \mathrm{street}$ width and error in enclosure index estimated by using Image-DSM. This figure demonstrates that narrow streets yield comparatively larger errors. Two major reasons for these large 
errors can be considered (Figures 11 and 12). One is that the heights at points in narrow streets were overestimated whereas heights at points on buildings facing streets were accurate (Figure 11(a)). The other reason might be that heights of buildings facing narrow streets were overestimated whereas heights of narrow streets were accurate (Figure 12(a)).

Occlusion maps for narrow streets generated by using LiDAR-DSM are more accurate than those generated by using Image-DSM. In Figure 13, occlusion maps estimated by using LiDAR-DSM are overlapped onto actual landscape in azimuth-elevation angle space. This figure demonstrates that LiDAR-DSM can be used for effective evaluation of enclosure indices. Therefore, it is concluded that LiDAR-DSM is more robust than Image-DSM with respect to estimating enclosure indices, and that Image-DSM should not be used for estimating enclosure indices in areas with narrow streets (less than $5 \mathrm{~m}$ in width).

\subsection{Computation time}

Computation time is among the most critical issues for application to wide areas. Figures 8(a) and 8(b) show the differences between results obtained for $E I_{1}$ and $E I_{2}$, respectively. It is clear that $E I_{2}$ was in general smaller than $E I_{1}$ because the portion of the area corresponding to the sky for $E I_{2}$ was smaller than that for $E I_{1}$. While $E I_{2}$ corresponds to a view closer to that of a human, the trend in terms of error is rather similar to that for $E I_{1}$. On the other hand, $E I_{1}$ requires less time to calculate than $E I_{2}$. In addition, the range of $E I_{1}$ is wider than that of $E I_{2}$, which is more appropriate to assess different degree of enclosure. Therefore, $E I_{1}$ is more suitable to use than $E I_{2}$.

The following discussion is focused on LiDAR-DSM-driven $E I_{1}$, based on the discussion in Subsection 5.1. Here, we examined the effect of the maximum search range $D_{\max }$ on computation time to calculate all points on ground (334,041): 37 minutes and 2.85\% RMSE for 50-m $D_{\max }, 70$ minutes and $2.72 \%$ for $100 \mathrm{~m}, 109$ minutes and $2.69 \%$ for $150 \mathrm{~m}$, and 173 minutes and $2.69 \%$ for $250 \mathrm{~m}$. The search was executed on a Windows 7 personal computer with an Intel Core i7 (3.20 GHz) processor and 6 GB of RAM. In the study area, the RMSEs of the two models were almost equal as long as $D_{\max }$ was $100 \mathrm{~m}$ or longer. However, when $D_{\max }$ was shorter than $100 \mathrm{~m}$, the RMSEs increased because there were high buildings located outside a short distance of each other. The optimization of $D_{\max }$ depends on the study area, and if high-rise buildings are dominant, $D_{\max }$ can be smaller than that used for the study area in this study. 
There may be several approaches to reducing the computation time. For example, although $\Delta \phi$ was set to $1^{\circ}$ in the experiment, it can be set to a higher value. Another way is to increase the grid size. It was found that RMSE increased for grids coarser than $1.0 \mathrm{~m}$. Because this parameter was found to be sensitive to the estimation error, other approaches to reduce the computation time should be examined in future studies.

\subsection{Calibration of LiDAR-DSM}

Black circles in Figure 8(a) show that the proposed algorithm underestimated enclosure indices. This was partly because data from airborne LiDAR were acquired in last-pulse mode. In the case of vegetation, the last-pulse mode may measure not the top of the vegetation surface, but rather the ground, trunks or branches. Therefore, more accurate estimation of the index may require calibration of the data if only last-pulse mode data are available. For example, the gain coefficient for converting original DSM data to pseudo-DSM data can be estimated using half of the data set of the actual enclosure index to minimize the sum of squared errors between the estimated and the actual enclosure index. The optimal gain coefficient as obtained by the authors was higher than 2.0. While this calibration failed, it may still be possible to estimate the gain coefficient for vegetation and that for other objects. In this case, the vegetation should be masked semi-automatically or manually using aerial images.

\subsection{Variation in enclosure index according to azimuth}

$E I_{1}$ is estimated by considering the entire range of $360^{\circ}$ for the azimuth at a specific cell. Figure 14 shows the $360^{\circ}$ azimuth range of the occlusion map at a specific cell was divided into two $180^{\circ}$ regions (denoted as A and B). This division was conducted so that the difference in enclosure indices between Regions A and B would be maximized. Figures 15(a) and 15(b) show the maximum and minimum enclosure index distributions, respectively. The divided ranges depend on location. Combinations of the two indices indicate that there are three types of landscape: (1) open spaces (low enclosure indices in all directions), (2) closed spaces (high enclosure indices in all directions), and (3) partly open spaces (low or high enclosure indices depending on direction). These combinations can provide more information about local landscape. 


\section{Conclusion}

This paper presented a definition of enclosure index and methodology for estimating it by using DSM. The index was defined as the ratio of occluded area to the entire field of view. It can assess local landscape from the viewpoint of a human, which is a new contribution to applications of DSM. Even though last-pulse mode data were available, the error rate of the index estimated by using LiDAR-DSM data was acceptable at approximately 3\%, whereas that of the index estimated by using Image-DSM data was approximately 7\%. It was because the height accuracy of LiDAR-DSM was higher than that of Image-DSM, especially for narrow streets (less than $5 \mathrm{~m}$ in width). Two enclosure indices, $E I_{1}$ in azimuth-elevation angle space and $E I_{2}$ in equisolid angle projection, were compared. $E I_{1}$ was selected because of less computation time and wider index range. The occlusion map can be calculated at any point of DSM, and the division of the azimuth range into two regions generates more information about enclosure pattern. Using this information, one possible application of the enclosure index is for assessing landscape in terms of traffic safety or security. In future, we will examine methodology to estimate other landscape indices including green space index.

\section{Acknowledgments}

This research was supported by a Grant-in-Aid for Scientific Research (KAKENHI) for Young Scientists (B) (24760412) by the Ministry of Education, Culture, Sports, Science and Technology. The authors would like to thank Dr. Keita Yamaguchi, Kyoto University, for providing advice from a viewpoint of landscape engineering and Wesco Co., Ltd., Okayama, Japan, for providing aerial photographs used in the experiments.

\section{References}

[1] Landscape Act, Ministry of Land, Infrastructure and Transport, Japan, 2004, available at http://www.mlit.go.jp/crd/townscape/keikan/pdf/ landscapeact.pdf (accessed on Mar. 31, 2012).

[2] Landscape Plan of Nishinomiya-city, 2011, available at http://www.nishi.or.jp/media/2011/ keikankeikaku_nishinomiya2011.pdf (accessed on Mar. 31, 2012).

[3] Goodwin, N. R., Coops, N. C., and Culvenor, D. S., "Assessment of forest structure with airborne LiDAR and the effects of platform altitude”, Remote Sensing of Environment, Vol. 103, Issue 2, pp. 140-152, 2006. 
[4] Houle, P. A., Zhang, K. Ross, M. S. and Simard, M., "Use of airborne LIDAR for the assessment of landscape structure in the pine forests of Everglades National Park”, Proceedings of International Geoscience and Remote Sensing Symposium, pp. 1960-1963, 2006.

[5] Secord, J. and Zakhor, A., "Tree detection in urban regions using aerial LiDAR and image data, IEEE Geoscience and Remote Sensing Letters, Vol. 4, No. 2, pp. 196-200, 2007.

[6] Yu, B., Liu, H., Zhang, L. and Wu, J., “An object-based two-stage method for a detailed classification of urban landscape components by integrating airborne LiDAR and color infrared image data: A case study of downtown Houston”, Proceedings of Urban Remote Sensing Event 2009, pp. 1-8, 2009.

[7] Carlberg, M., Gao, P., Chen, G. and Zakhor, A., “Classifying urban landscape in aerial LiDAR using 3D shape analysis”, Proceedings of 16th IEEE International Conference, pp. 1701 - 1704, 2009.

[8] Zhou, W. and Troy, A., "An object-oriented approach for analysing and characterizing urban landscape at the parcel level”, International Journal of Remote Sensing, Vol. 29, No. 11, pp. 3119-3135, 2008.

[9] Zhang, J. X. and Lin, X. G., “Object-based classification of urban airborne lidar point clouds with multiple echoes using SVM", ISPRS Annals of Photogrametry, Remote Sensing and Spatial Information Sciences, Vol. I-3, pp. 135-140, 2012.

[10]Goodwin, N. R., Coops, N. C., Tooke, T. R., Christen, A. and Voogt, J. A., “Characterizing urban surface cover and structure with airborne lidar technology”, Canadian Journal of Remote Sensing, Vol. 35 No. 3 pp. 297-309, 2009.

[11]Yu, Bailang, Liu, Hongxing, Wu, Jianping, Hu, Yingjie, \& Zhang, Li., “Automated derivation of urban building density information using airborne LiDAR data and object-based method", Landscape and Urban Planning, Vol. 98 No. 3-4, pp. 210-219, 2010.

[12]Alexander, Cici, Smith-Voysey, Sarah, Jarvis, Claire, \& Tansey, Kevin, "Integrating building footprints and LiDAR elevation data to classify roof structures and visualise buildings", Computers, Environment and Urban Systems, Vol. 33, No. 4, pp. 285-292, 2009).

[13]Match-AT, Inpho, available at http://www.inpho.de/index.php?seite= index_match-at (accessed on Mar. 31, 2012). 
[14]Match-T DSM, Inpho, available at http://www.inpho.de/index.php?seite=index_match-t (accessed on Mar. 31, 2012).

[15]50-m DEM, Geospatial Information Authority of Japan, available at http://www.gsi.go.jp/ geoinfo/dmap/dem50m-index.html (accessed on Mar. 31, 2012).

[16]Susaki, J., “Adaptive slope filtering of airborne LiDAR data in urban areas for digital terrain model (DTM) Generation”, Remote Sensing, Vol. 4, pp.1804-1819, 2012. 
Figure captions

Figure 1. Maximum elevation angle $\theta_{\max }$ at which occlusion by objects is present from the viewpoint of a human of height $h$ along azimuth $\phi$ within the maximum range $D_{\max }$.

Figure 2. Calcuation of enclosure index. (a) Enclosure index $1\left(E I_{1}\right)$ in azimuth-elevation angle space, and (b) Enclosure index $2\left(E I_{2}\right)$ in equisolid-angle projected space.

Figure 3. Search along azimuth $\phi$.

Figure 4. Aerial photograph of the study area $(927 \mathrm{~m} \times 1144 \mathrm{~m})$. Yellow cross denotes verification points where measurements were conducted using a digital camera with a fisheye lens.

Figure 5. Estimated $E I_{1}$ using LiDAR-DSM. Gray denotes non-ground points where estimation was not conducted.

Figure 6. Estimated $E I_{1}$ using Image-DSM.

Figure 7. Measurement using images acquired with a digital camera with a fisheye lens. (a) Forward viewing angle and (b) backward viewing angle. Areas corresponding to the sky areas are shown in blue. The locations of the surveys are denoted with yellow crosses in Figure 1.

Figure 8. Comparison between estimated and actual enclosure indices. (a) $E I_{1}$ from LiDAR-DSM and Image-DSM and (b) $E I_{2}$ from LiDAR-DSM and Image-DSM.

Figure 9. Relation between road/street width and height difference between Image-DSM and LiDAR-DSM.

Figure 10. Relation between road/street width and the error in the enclosure index estimated by using Image-DSM.

Figure 11. Error type 1 for narrow streets in Figure 10 (a) Estimated Image-DSM (dashed line and crosses), viewing direction (solid line) and actual viewing direction (chain line), (b) estimated landscape in azimuth-elevation angle space, and (c) actual landscape in azimuth-elevation angle space. Cell brightness in (b) was reprojected from aerial images.

Figure 12. Error type 2 for narrow streets in Figure 10 (a) Estimated Image-DSM (dashed line and crosses), viewing direction (solid line) and actual viewing direction (chain line), (b) estimated landscape in azimuth-elevation angle space, and (c) actual landscape in azimuth-elevation angle space. Cell brightnesss in (b) was reprojected from aerial images. 
Figure 13. Enclosure index estimated by using LiDAR-DSM. Estimated landscape is overlapped onto actual landscape in azimuth angle-elevation angle space. Red denotes DSM except roads, and blue denotes roads obtained by filtering.

Figure 14. Division of azimuth range for generating maximum and minimum enclosure indices.

Figure 15. Estimated (a) maximum and (b) minimum enclosure index. 


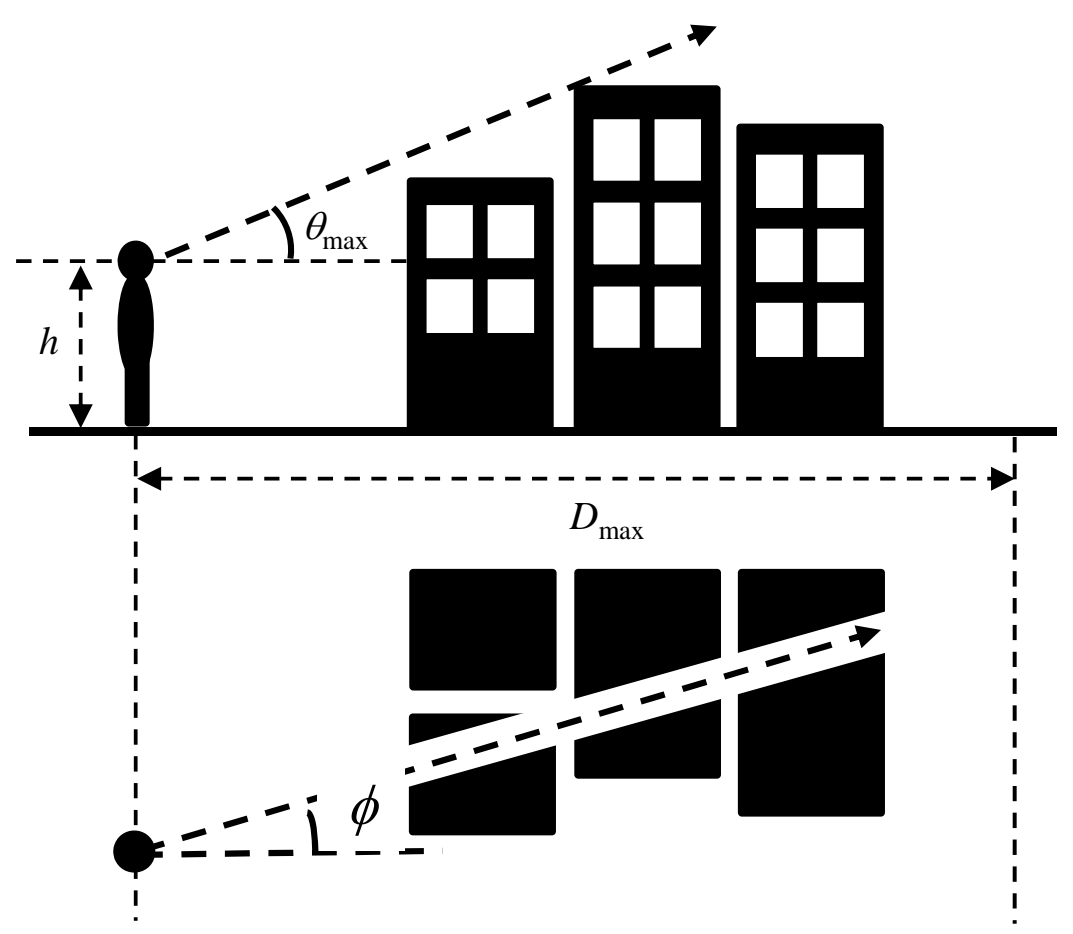

Figure 1.

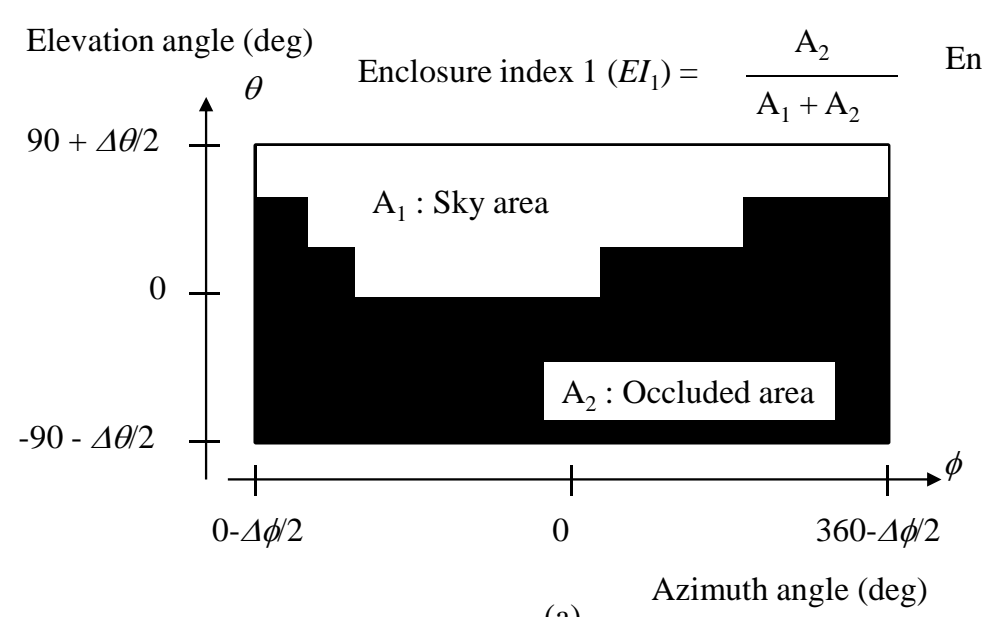

(a)
Enclosure index $2\left(E I_{2}\right)=\frac{\mathrm{B}_{2}}{\mathrm{~B}_{1}+\mathrm{B}_{2}}$

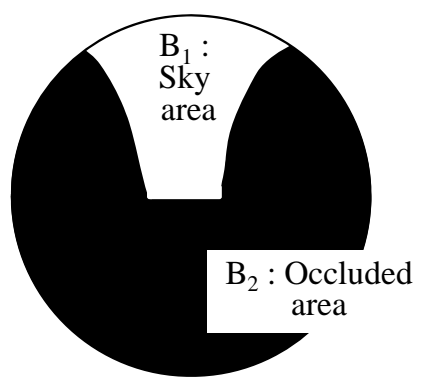

(Equisolid angle projection)

(b)

Figure 2. 

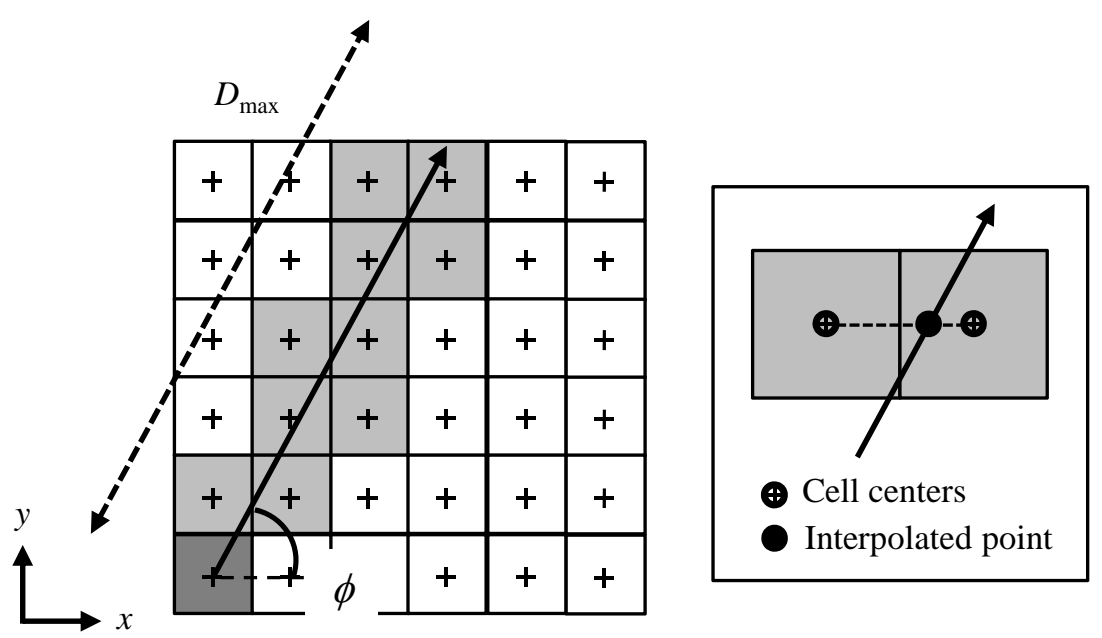

Figure 3.

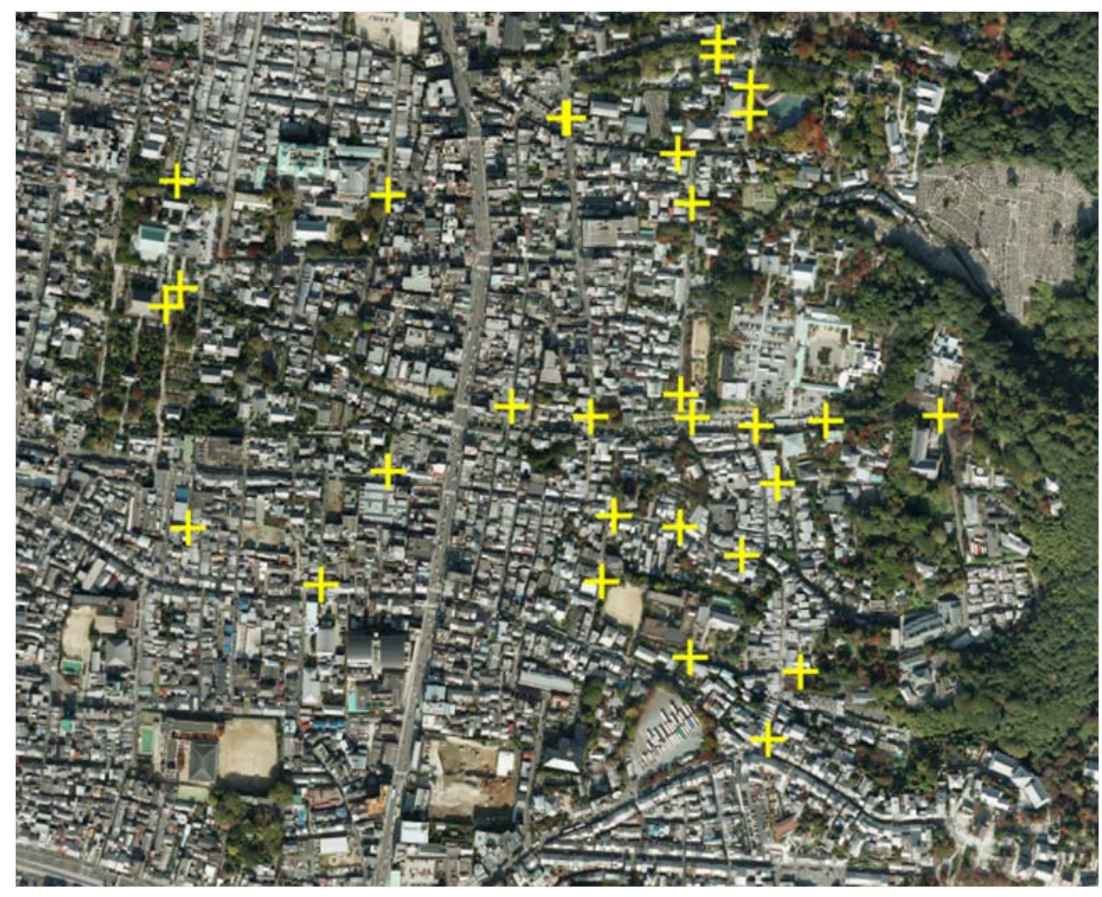

$0 \quad 125 \quad 250$

$500(\mathrm{~m})$

Figure 4. 


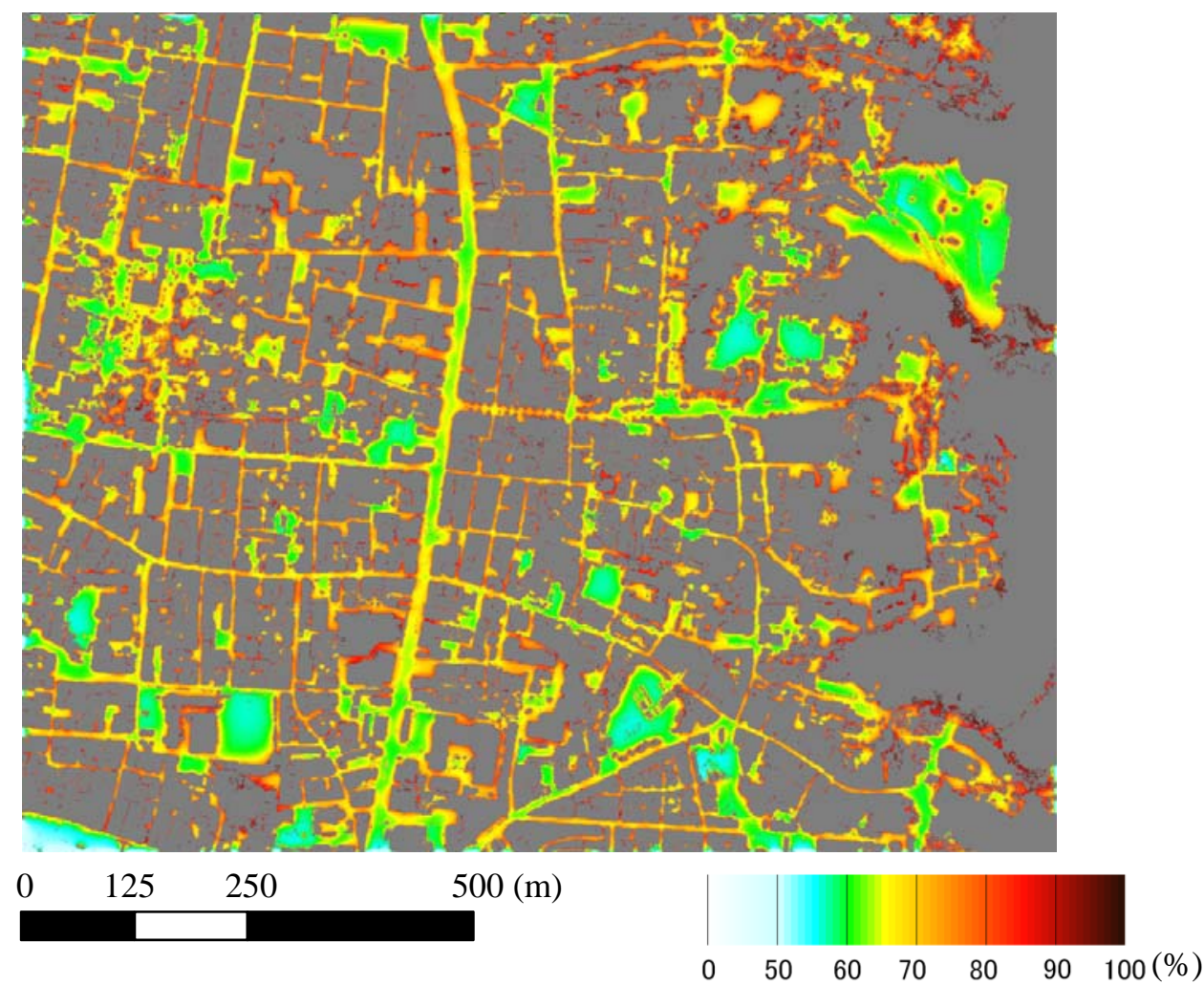

Figure 5.

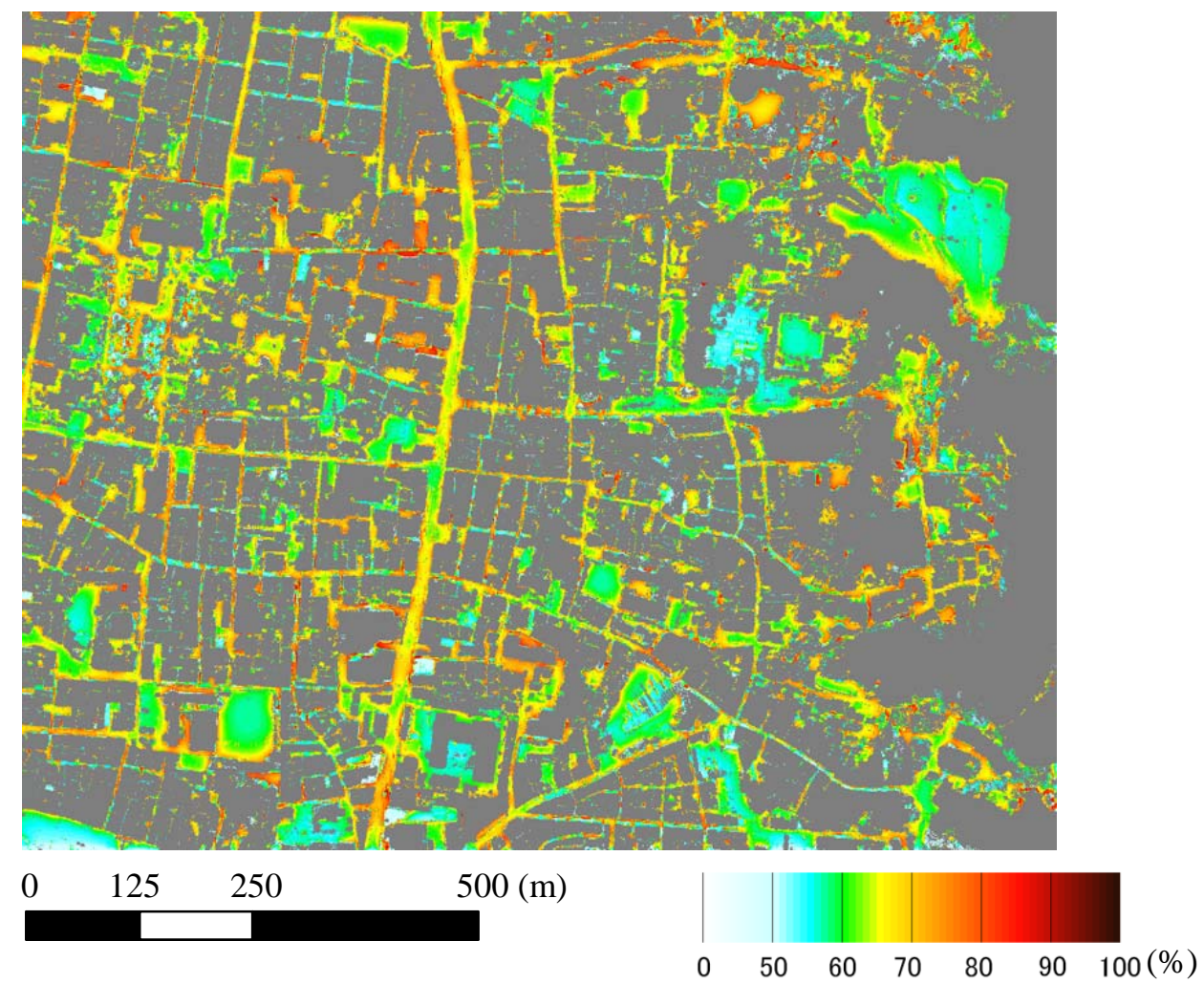

Figure 6. 


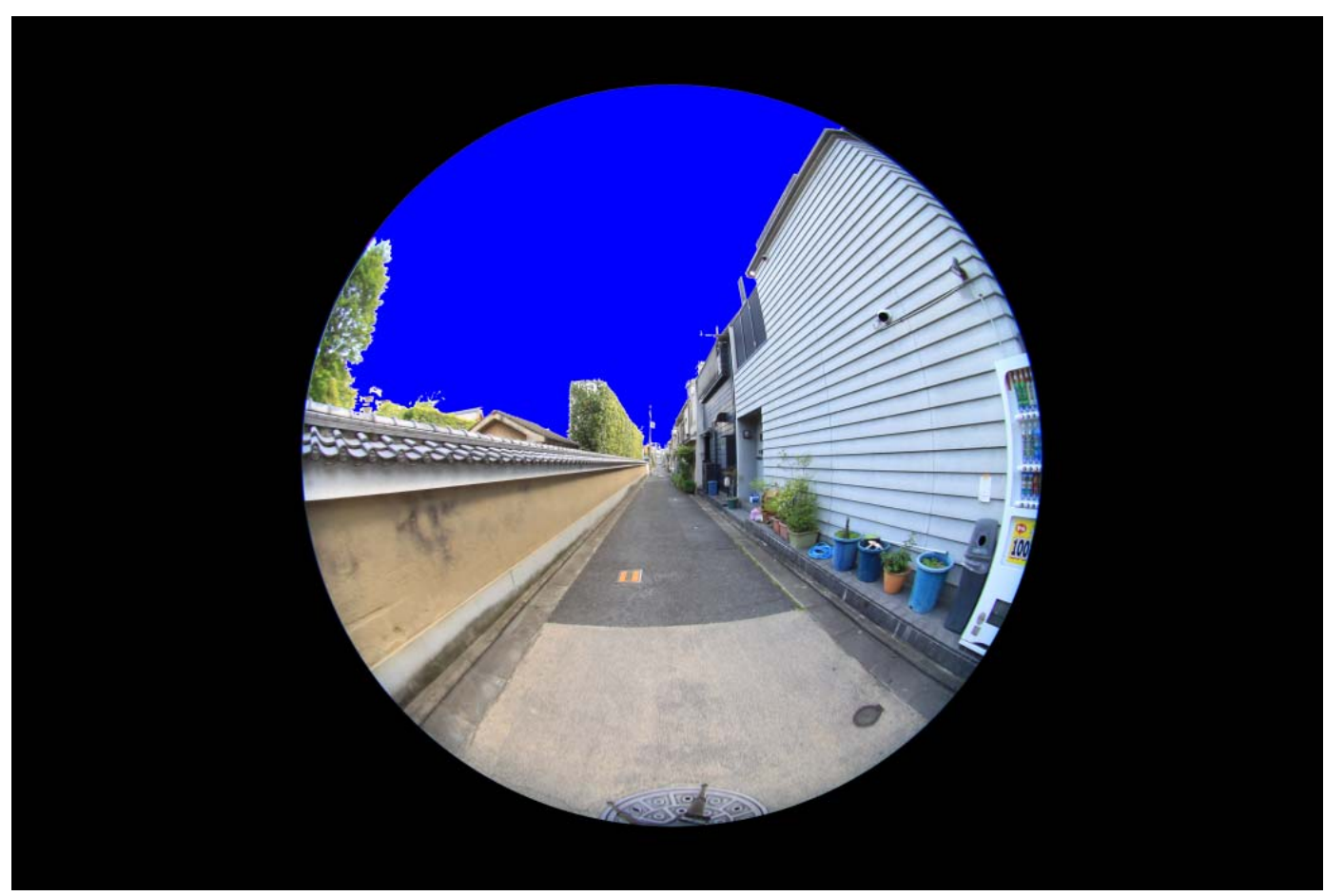

(a)

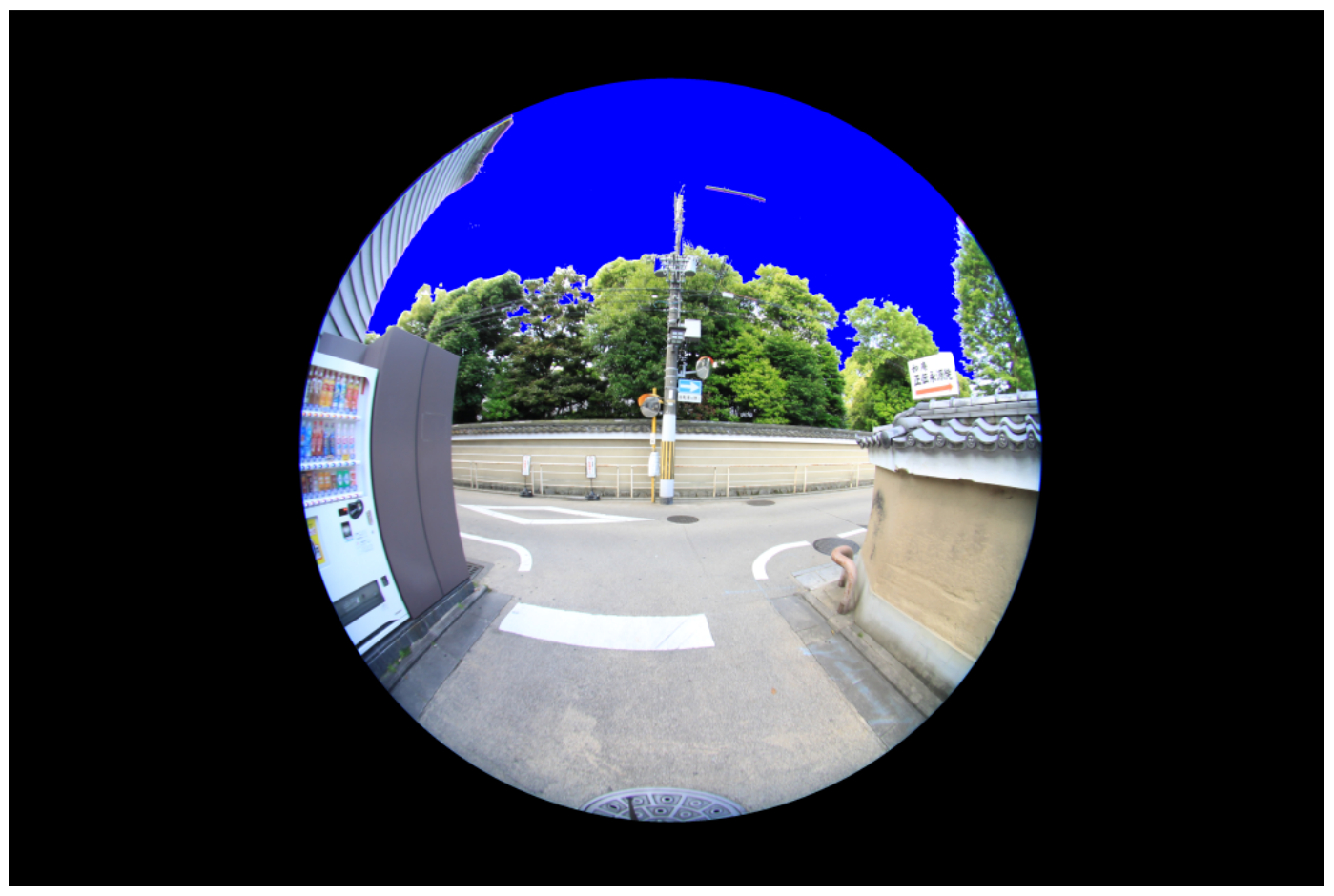

(b)

Figure 7. 

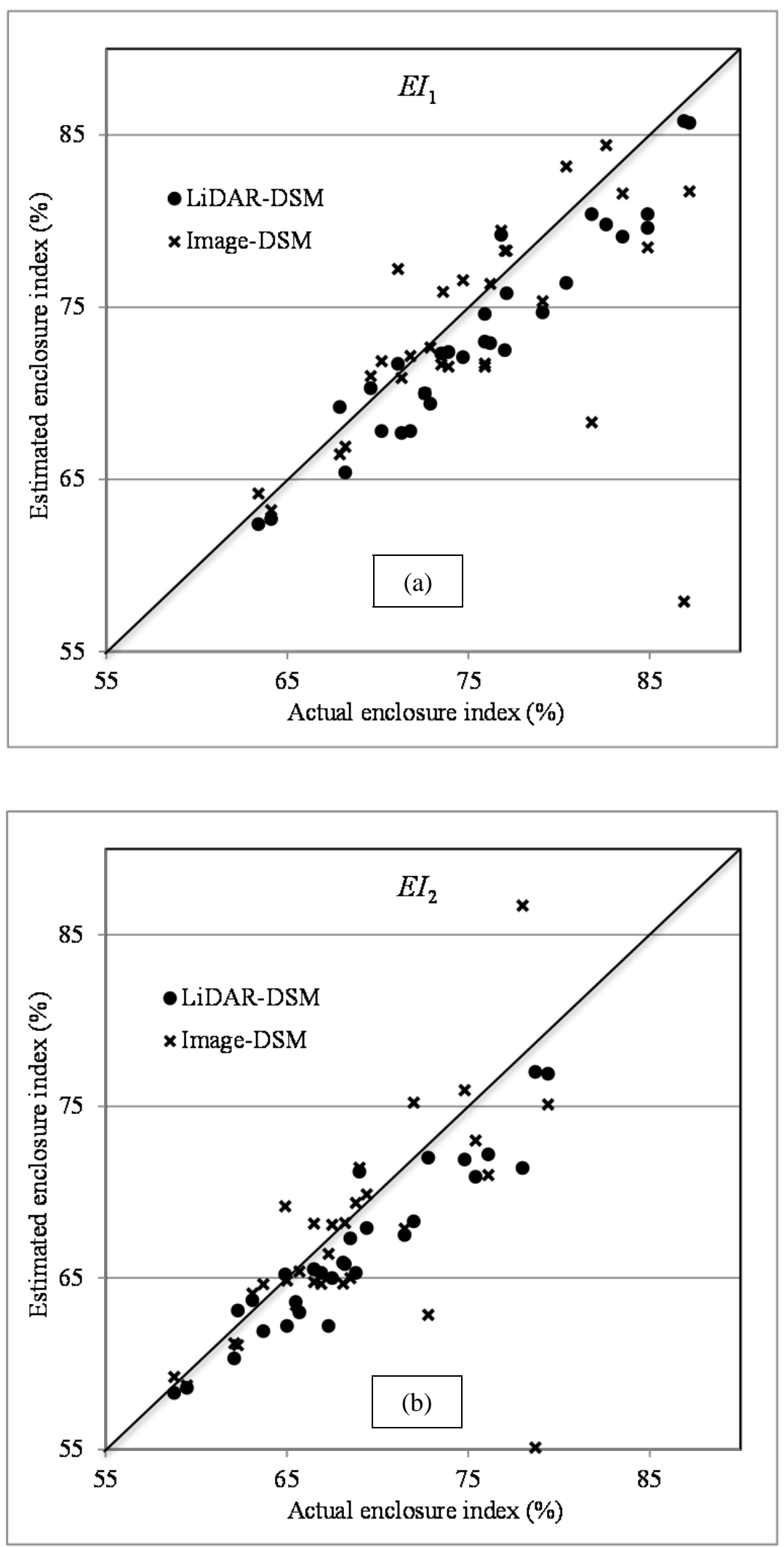

Figure 8. 


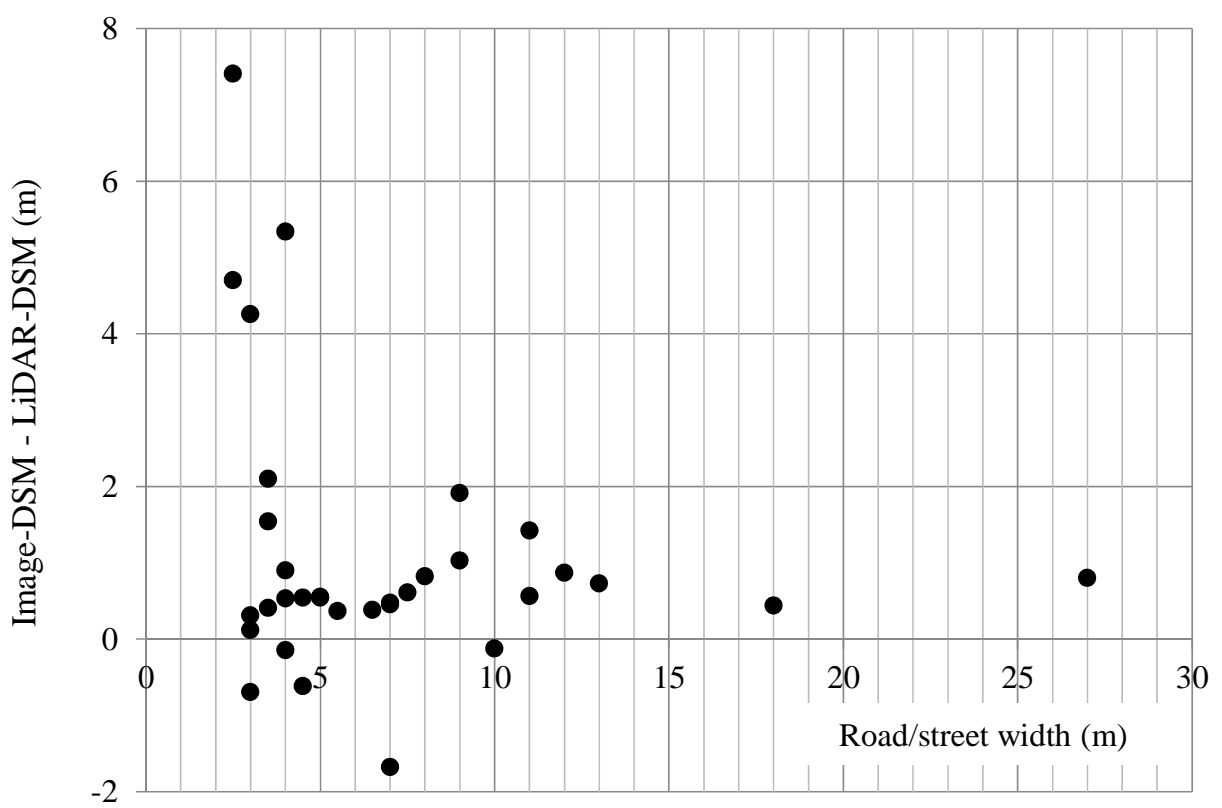

Figure 9.

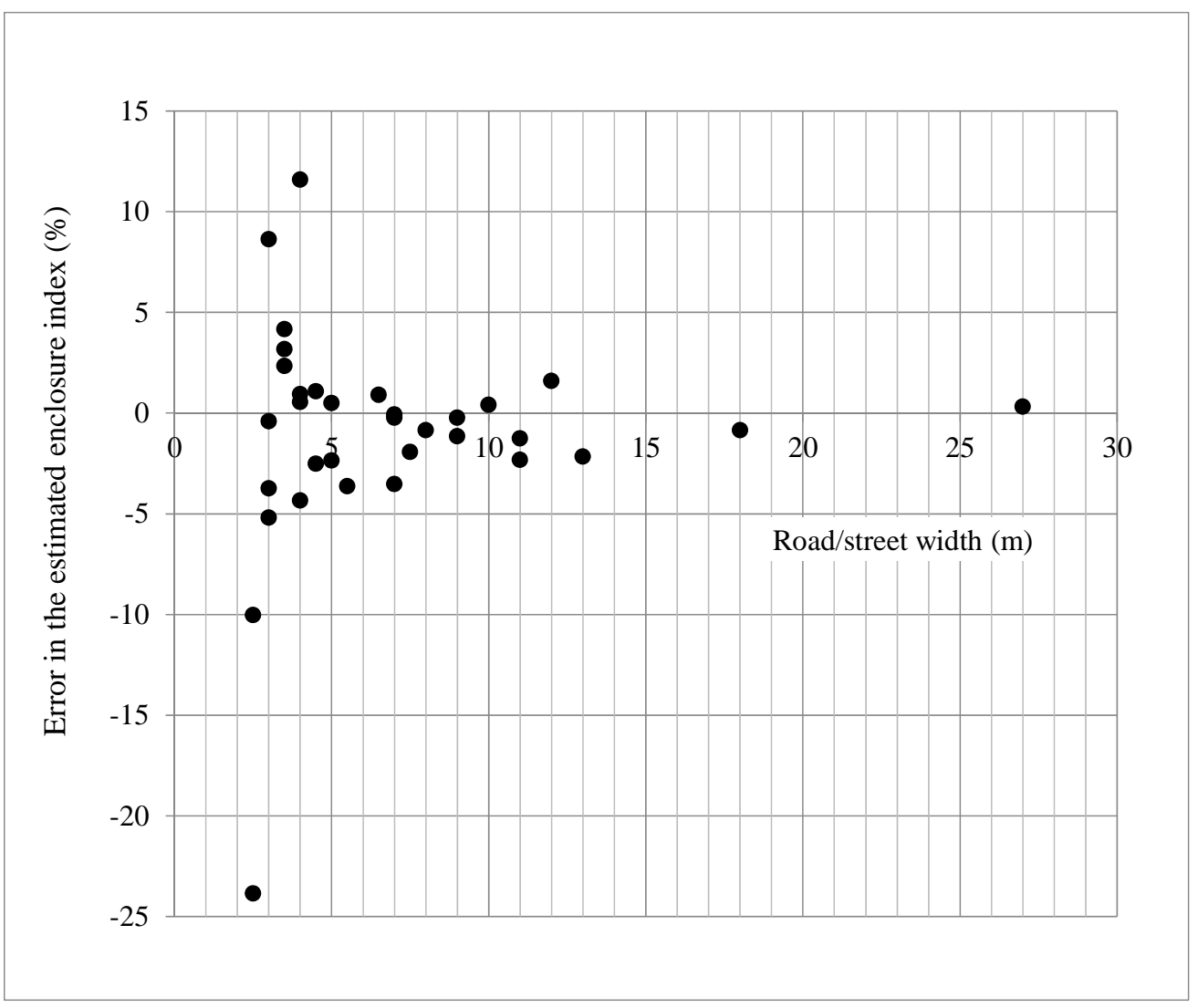

Figure 10. 


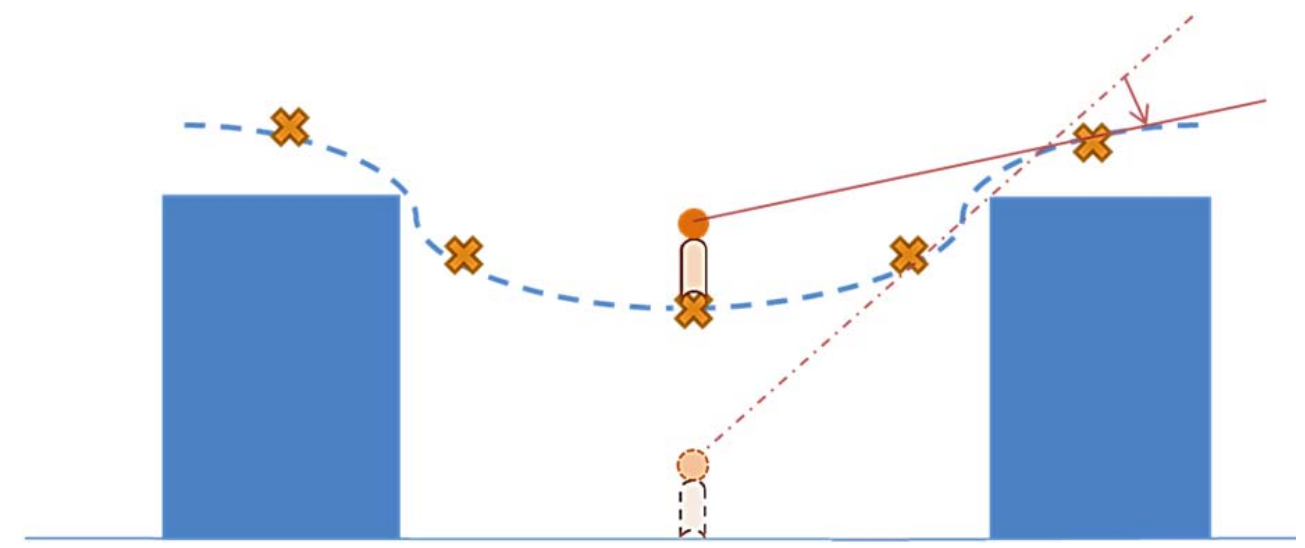

(a)



(b) Estimated $E I_{1}=54.1 \%$

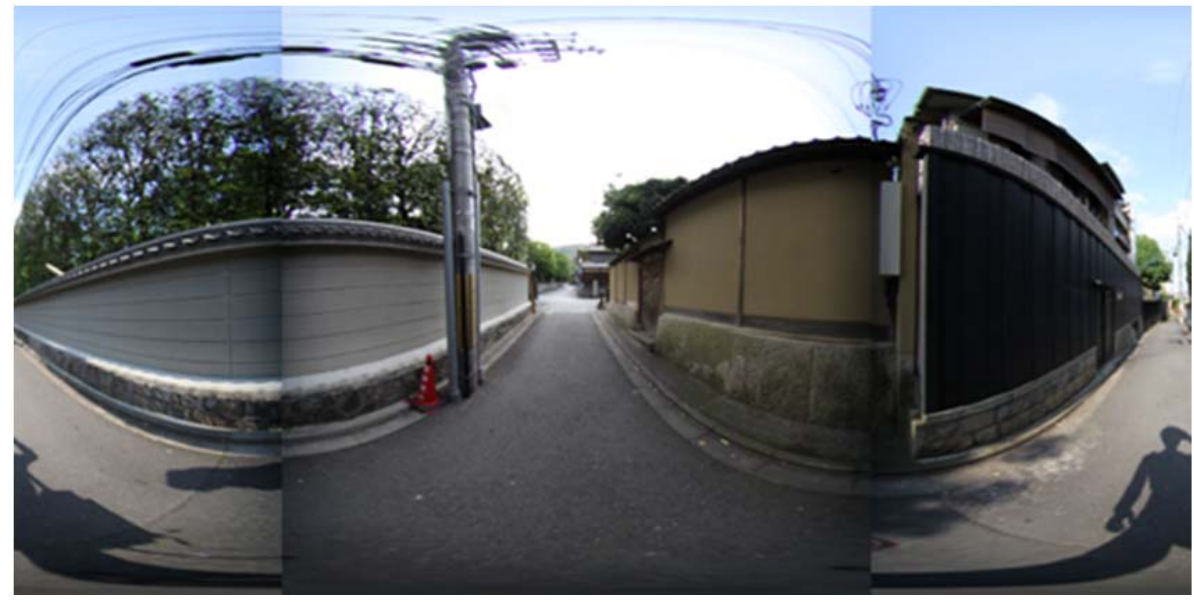

(c) Actual $E I_{1}=79.0 \%$

Figure 11. 


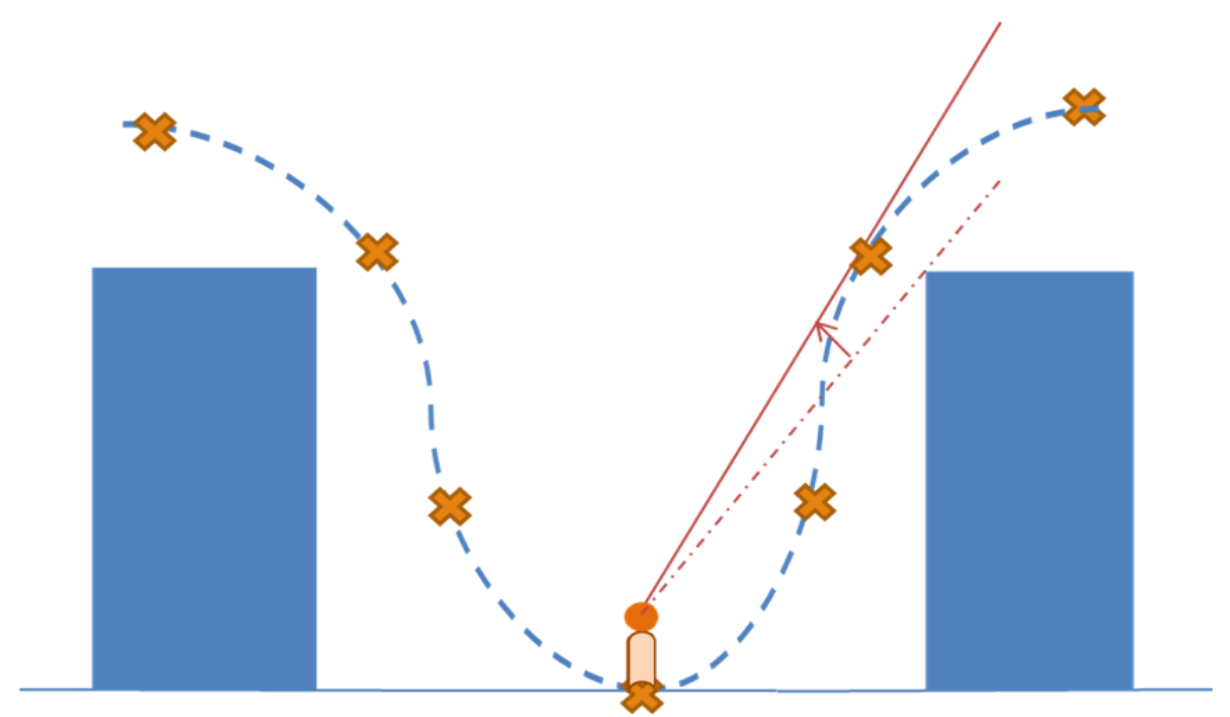

(a)

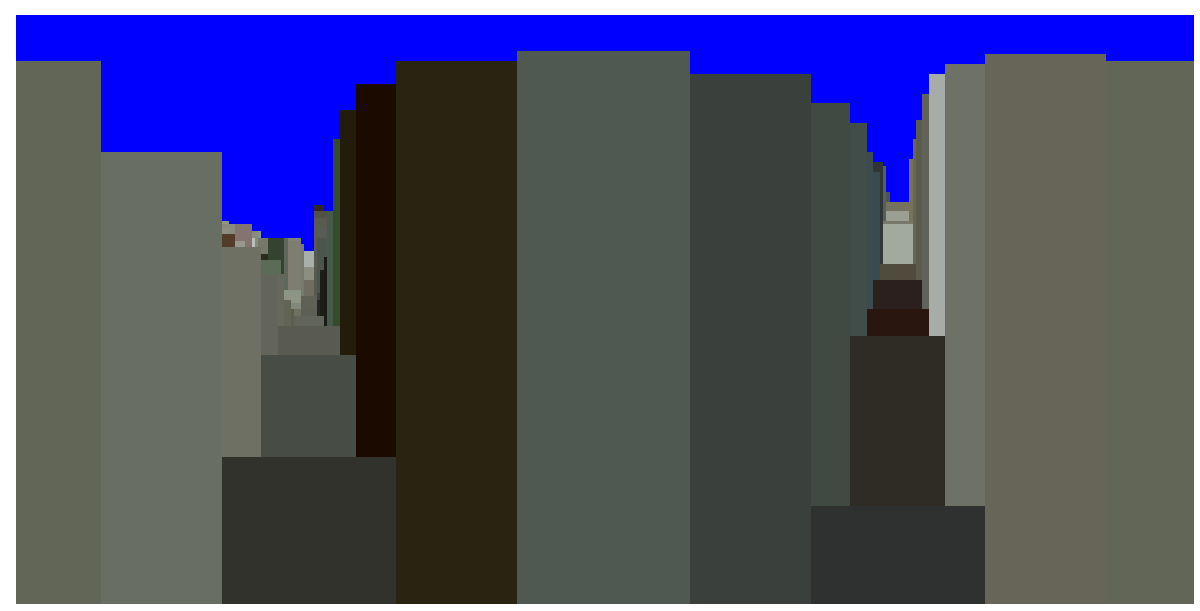

(b) Estimated $E I_{1}=86.7 \%$

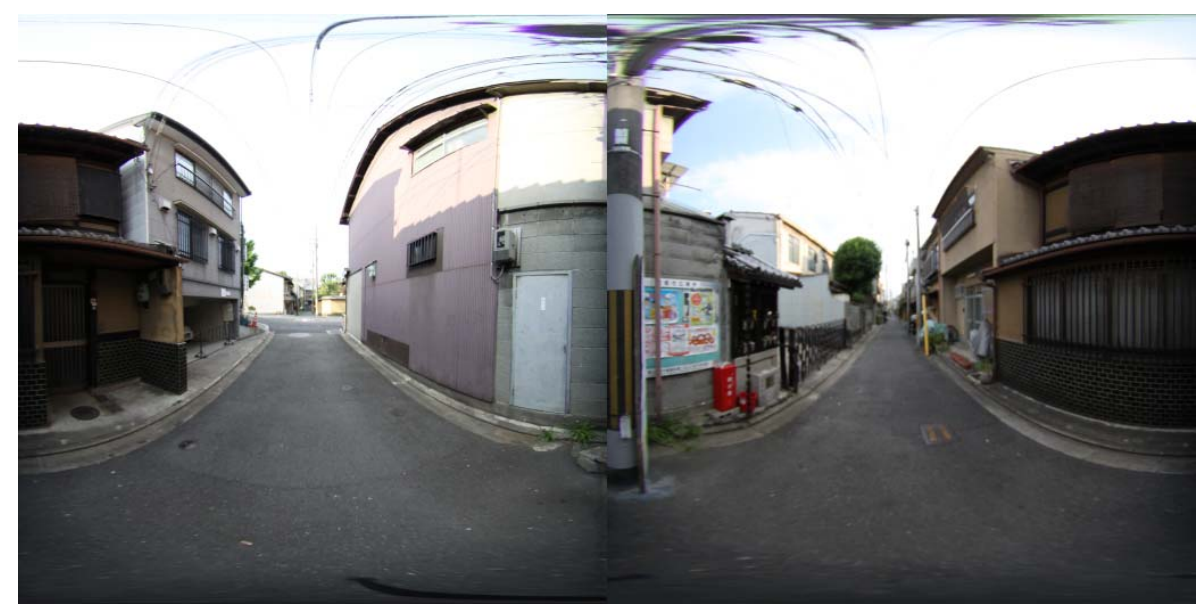

(c) Actual $E I_{1}=78.1 \%$

Figure 12. 


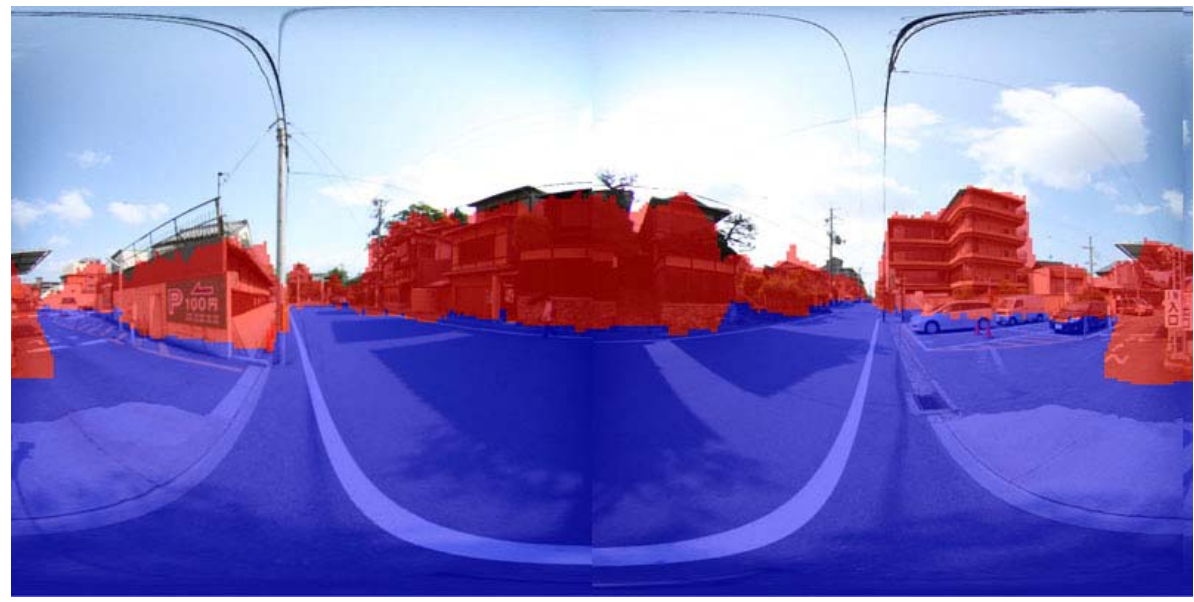

(a) Estimated $E I_{1}=60.3 \%$, actual $E I_{1}=62.1 \%$, Estimated $E I_{2}=65.4 \%$, actual $E I_{2}=68.2 \%$

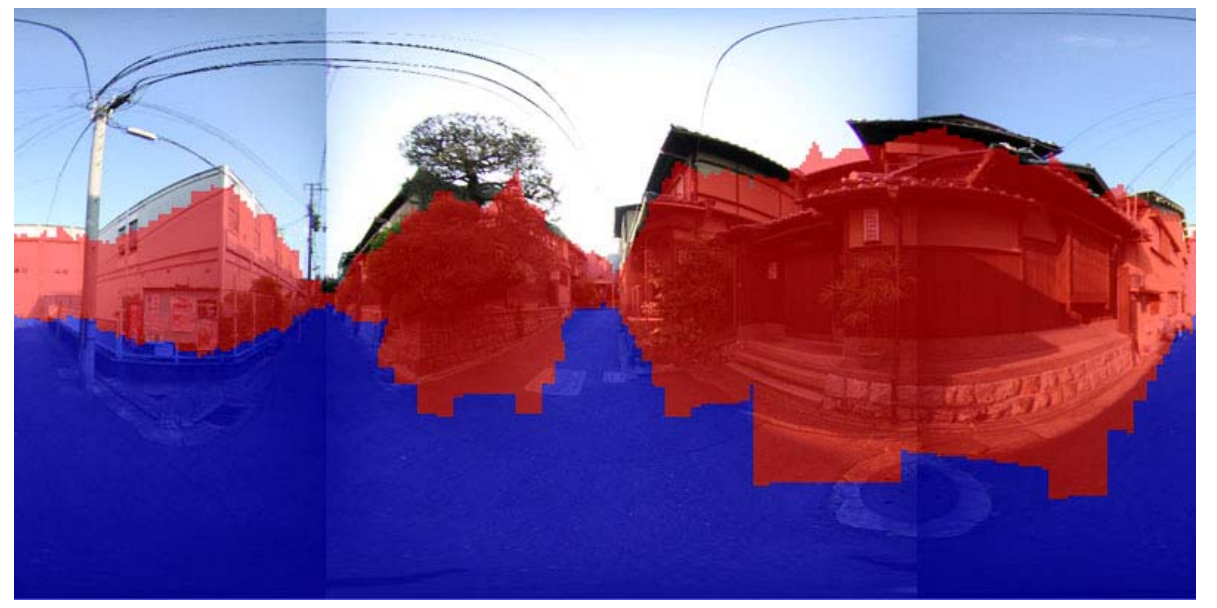

(b) Estimated $E I_{1}=68.3 \%$, actual $E I_{1}=72.0 \%$, Estimated $E I_{2}=76.4 \%$, actual $E I_{2}=80.4 \%$

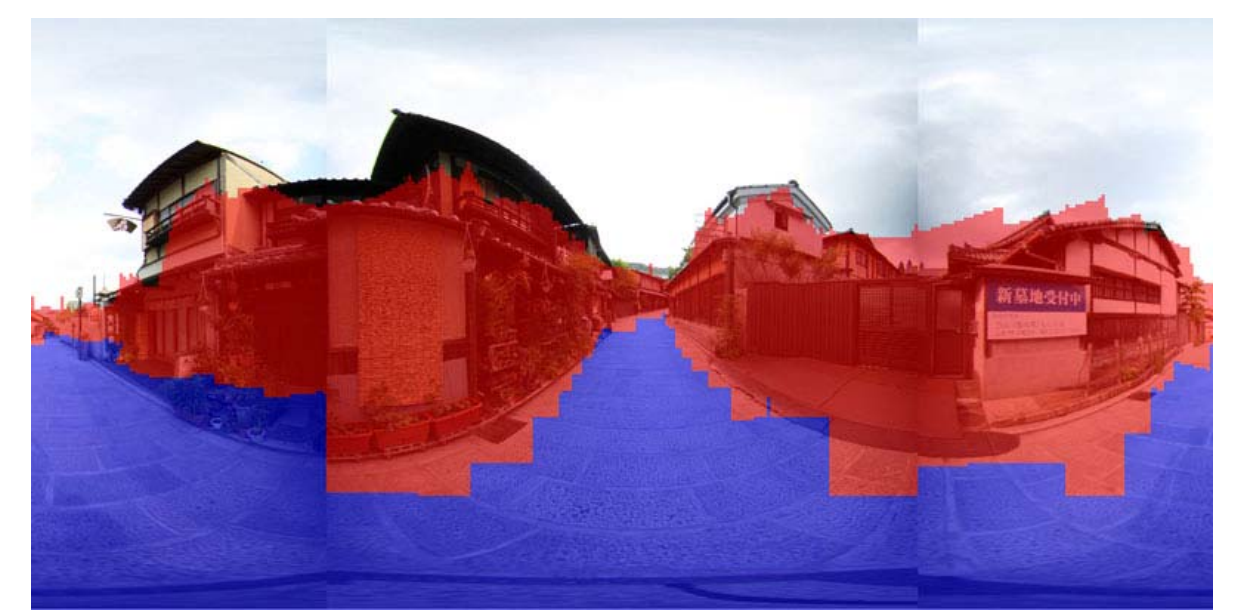

(c) Estimated $E I_{1}=65.0 \%$, actual $E I_{1}=67.5 \%$, Estimated $E I_{2}=72.1 \%$, actual $E I_{2}=74.7 \%$

Figure 13. 


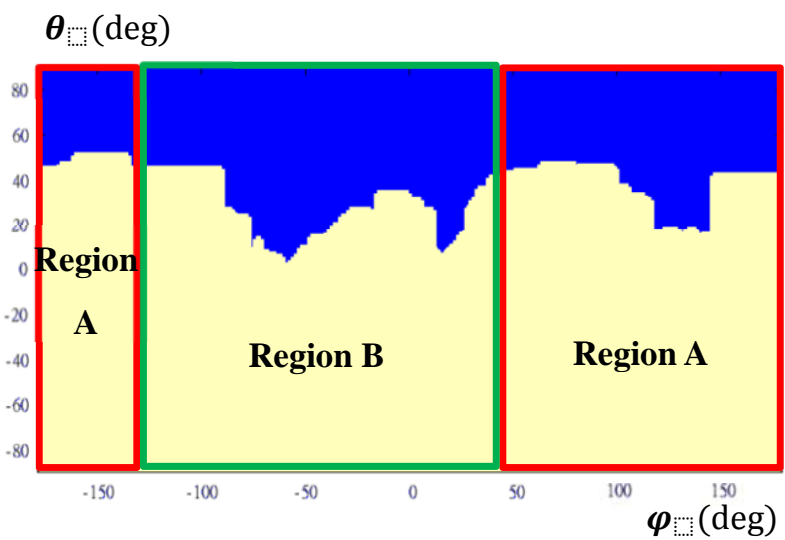

Figure 14.
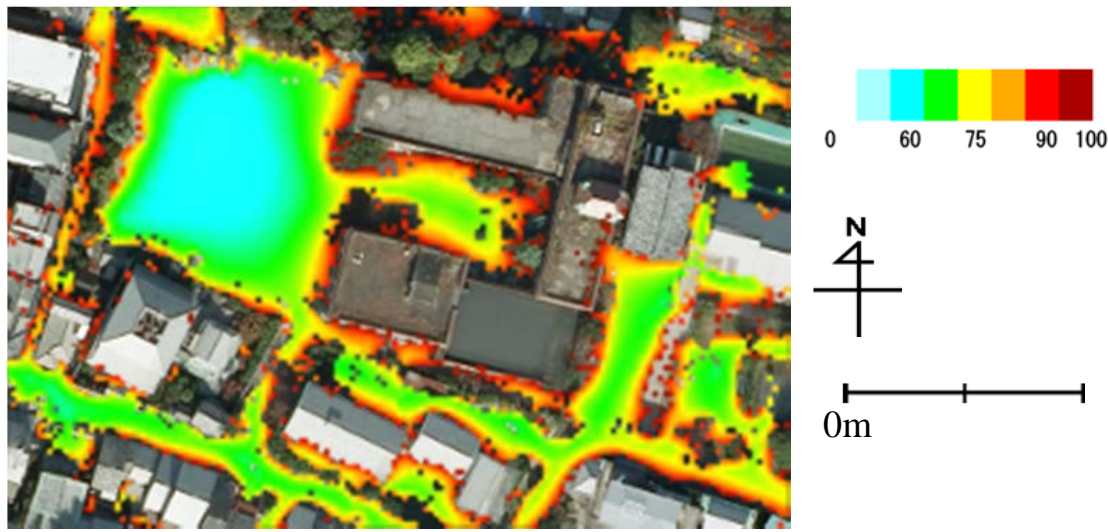

$\stackrel{\longmapsto}{0 m}$

(a)

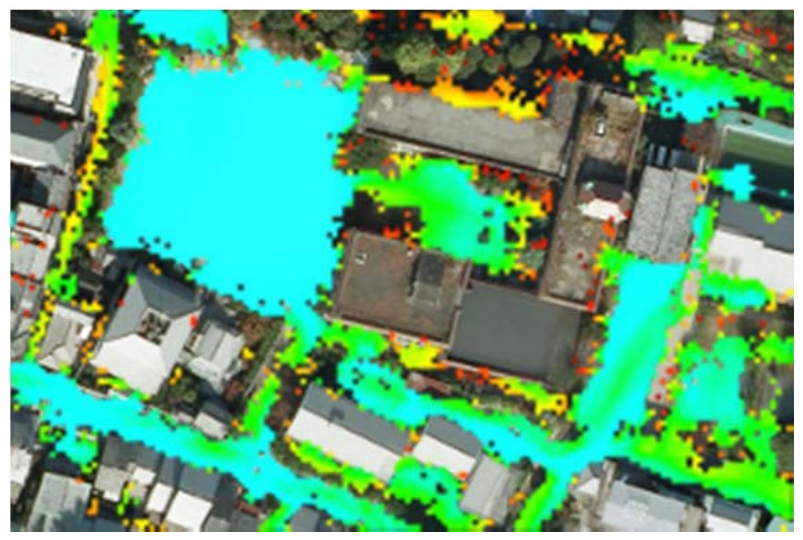

(b)

Figure 15. 